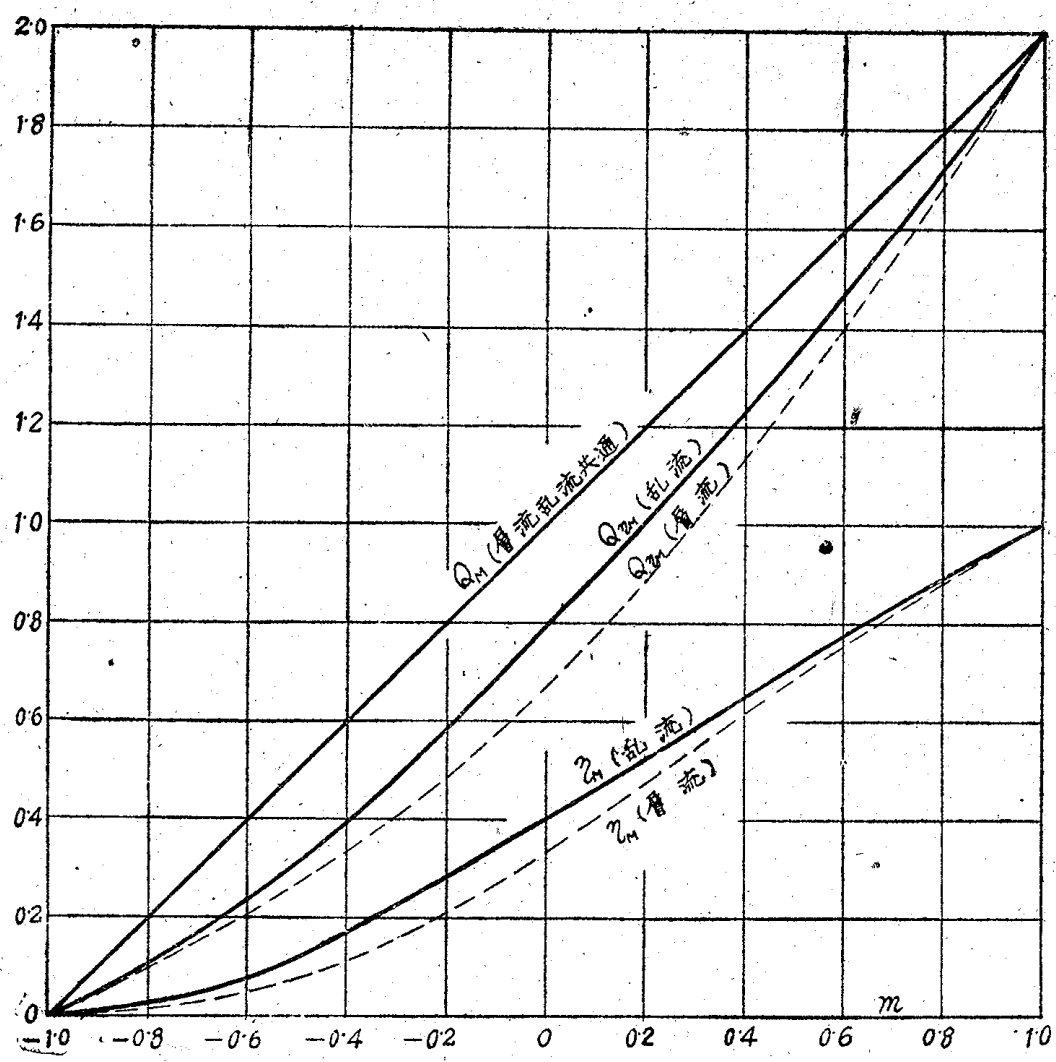

第 6 図 乱流特性值 $Q_{M}, Q_{\eta M}, \eta_{M} \varepsilon m$ 之D関係
における $Q$.

一般的結覦として效穿は乱れによつて 理諭上向上することがわかる。

培 :-

(1) 昭利 21 年 11 月 30 日 485 回 講演会において請演，源稿受附炤和。 22 年 10 月 24 日，諭文は「礐擦ポン プ乱流特性の研究」と題しま之めて追 つて發表の予定。

(2) 正負, 東京大学筤二工学部.

(3) 富津，機㭜学会 諭文集，10 告 40 号 (第 3 部), III $-40 \sim$ III -54 頁 (昭 $19-8,11), 13$ 夋, 43 歺, 89 94 頁 (昭 22-1).

(4) 宮津, 同諭文集, 13 参 43 号\% $94 \sim 100$ 頁 (昭 22-1).

\title{
Gibson 水量計測法における水銀柱の振動とそれによつて
} 生ずる計測誤差についで?

水力発電所などにおける大きな流量の計測法として Gibson法が発表せられてから早や 20 数年になる(3). この方法の要点はつぎのごとくである。第1図におい てPは水压鉄管を示す. 水圧鉄管內を定常的流量 $Q か 5$ 流れているときこれを計測するために計測個所の下

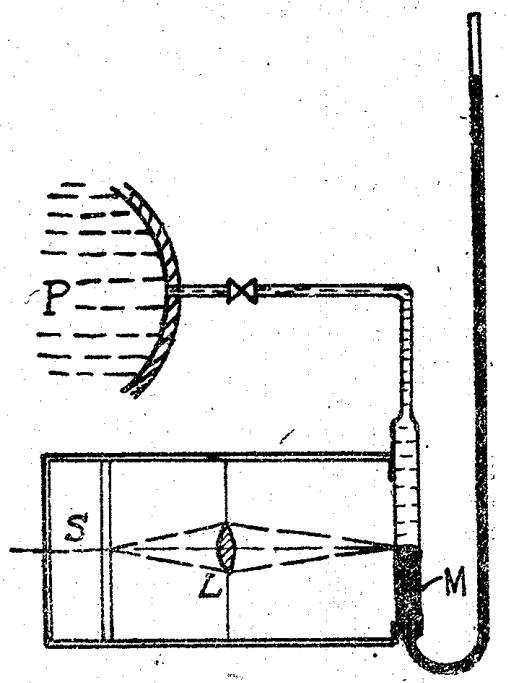

第 1 图 Gibson 水量計測法におけ乃記錄裝置
流に設てある弁(水力発電所の場合には水車の導旸根) を閉ちて鉄管內に緩やかな水桹作用をおこさせる。文 の压力上杽を水銀杜マノメーター $M$ に傳え, それの 動きをレンズ $L$ をへて記銭悢 $S$ に記錄する。時間 $\boldsymbol{t}$ と压力上鼠との関係をこのようにして記錄したものは たとえば第 2 図のようになる。図に少いて $H_{1}$ は弁を

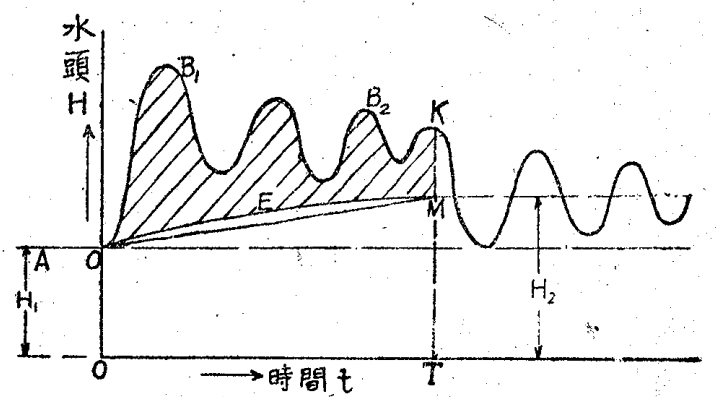

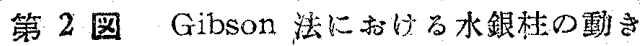

閉ぢる前の定常的水頭， $H_{2}$ は閉ぢた後の定常的水頭 である. $H_{2}-H_{1}$ は海量 $Q$ のための計测個所におけ る水頭低下㽞である。曲線 $O B_{1} B_{2} K$ は上記の!昇圧 力の曲線である，Tは閉ちるに要した時間である。弁 
を閉ぢてゆくにしたがつて鉄管內の流速は減少してゆ くから, 訢測個所の水頭は (もし水槌作用がなければ) 時間と共にOENのごとく変化するものと推定され る. Gibson はこの曲線 $O E M$ を推算する方法を考え ている，運動量の理論に上つて，曲線 $O E M$ と曲線 $O B_{1} B_{2} K$ とに挾むれた面積（荟線をつけた）は流量 $Q$ に比例することとなり，この面積を計ることによつ てQ $Q$ を求的うとをすのが Gibson 法の骨子である。

ところが䒠情を調べてみるといろいろ疑問がおこる のであうて，たとえば氷の压穛性の影響を無䤄した上 のような訐算法が正しいものかどうかについても， Gibson $^{(3)}$ や Thoma ${ }^{(4)}$ は餘りふれていない. Lかし さらに重大な問題として承銀柱マノメーターが果して 本当の圧力変動を表わしているかどうかとの問題がお こる. 仗りに水銀社は各瞬間に抲いて本当の压力变動 を表わしてお方ず，压力変動曲線 $O B_{1} B_{2} K$ は多分に 水銀桂の自己振動を含んでいるとしても，本均におい てこれは帳消しにされ，面積 $O B_{1} B_{2} K M E O$ は $Q$ に比例するようになるのではないか，との議論もおこ り得る。これらの点を以下においてカ学的に調べてみ 上了。

まず弁を閉ぢたときいかなる圧力変動がおこるかを 見定める必要がある。こっで恃第 3 図に示すような適
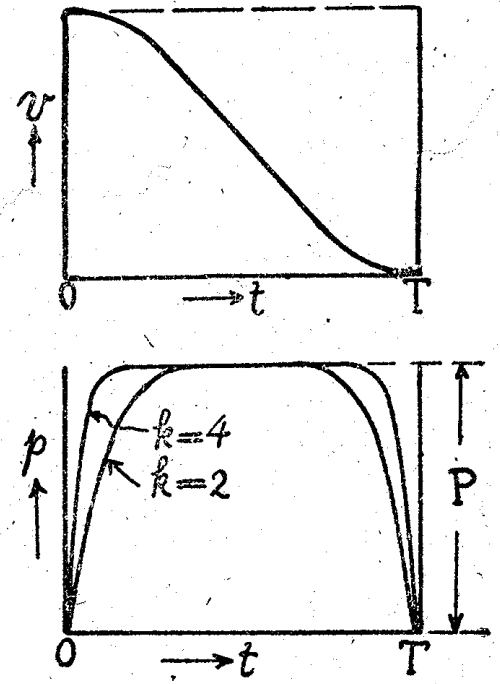

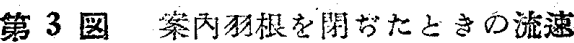
和よび壓门纂化

当な変動政線を想定すれば足りる。実祭の压力変動曲 線はもちろんかなり複雜な形をしている。この压力の 変り方を数式

$$
p=P\left[1-e^{-\lambda t}-e^{-\lambda(T-t)}\right]
$$

で路近的に表わそう、入は畔線の曲りの銳さを指定す る常数であつて $\lambda T=k \pi$ とおくとき，たとえば $k=2$ または $k=4$ ととれば第 3 図の上うな曲線がえられる。 摩蔡抵抗は速度に此例すると考えたとき，上のよう な压力の作用をうける水銀杜の動きは微分方程式

$$
m \frac{d^{2} x}{d t^{2}}+b \frac{d x}{d t} \cdot x x=P\left[1-e^{-\lambda t}-e^{-\lambda(T-t)}\right]
$$

によつて定められる。さいに $m, b, a$ は文れぞれ水 銀杜の質量，縻擦抵抗，比重に関係ある常数である. 微分方程式 (2) の解梳

$$
\begin{aligned}
& x=A \sin (\omega t+\varphi) e^{-\mu t} \\
+ & P\left[\frac{1}{a}-\frac{1}{\lambda m-b \lambda+a} e^{-\lambda t}-\frac{1}{\lambda^{2} m+b \lambda+a} e^{-\lambda(\boldsymbol{T}-t)}\right]
\end{aligned}
$$

となる・ただし

$$
\left.\begin{array}{l}
\omega=\omega_{0}\left[1-\frac{1}{4}\left(\frac{b}{a}\right)^{2} \omega_{0}^{2}\right]^{1 / 2} \\
\mu=\frac{b}{2 m} \quad \omega_{0}^{2}=\frac{a}{m}
\end{array}\right\}
$$

としてある、 $A, \varphi$ はいわゆる任意常数であつて，初 期 $t=0$ に执いて $x=0, d x / d t=0$ なる條件によつて これを定めればつぎの゙とくになる。ただじ六T、 は 1 に比し船哯しうるものとする。

$$
\begin{aligned}
& A \sin \varphi=-\frac{P}{a}\left[\frac{\lambda^{2} m-b \lambda}{\lambda^{2} m-b \lambda+a}\right] \\
& A \cos \varphi=-\frac{P}{a} \frac{\lambda}{\omega_{0}}\left[\frac{a+\lambda \mu m-\mu b}{\lambda^{2} m-b \lambda+a}\right] \\
&|A|=\frac{P}{a\left(\lambda^{2} m-b \lambda+a\right)}\left[\lambda^{2} m-b \lambda\right]^{2} \\
&\left.\quad+\left(\frac{\lambda}{\omega_{0}}\right)^{2}(a+\lambda \mu m-\mu b)^{2}\right]^{1 / 2}
\end{aligned}
$$

つきに $x-t$ 曲線の面䖽を求めると

$$
\begin{aligned}
A_{1}= & \int_{0}^{T} x d t \\
= & i p \frac{A}{\sqrt{\omega^{2}+\mu^{2}}} e^{-i \beta+i \varphi}\left[e^{-\mu T+i \omega T}-1\right] \\
& +P\left[\frac{T}{a}-\frac{1}{\lambda\left(\lambda^{2} m-b \lambda+a\right)}-\frac{1}{\lambda\left(\lambda^{2} m+b \lambda+a\right)}\right]
\end{aligned}
$$

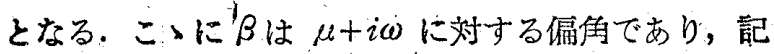
号 $i, p$ は数式の㫌数部をとるべきことを意味するも のとする。

これに対し，水銀社の䝷量 $m$ が 0 である理想的の 場合には，同し面積は，(2)によb:( $m=b=0$ とおく ことにより)

$$
A_{2}=\frac{P}{a}\left[T-\frac{1}{\lambda}-\frac{1}{\lambda}\right]
$$

となるのである。そこで雨者の差 $A_{2}-A_{1}$ をとり， これをPT/aでわつた比を $R$ と名付けるときはこの

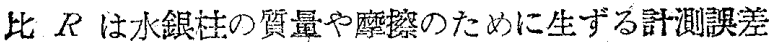
の目策になるであろう。

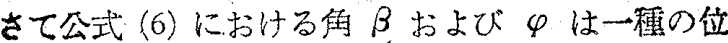


相侯であり水銀裎自身の固有振動数によつて支配され るものである。式（6）の中にはこの外に $\omega T$ が位相 解の形ではいつているが，これは水銀栍の自己周期と 升を閉ちる時間 $T$ との比を表わすものである。閉ち る時間 $T$ と水銀柱の固有拉動数との間に一定の関係 は存在しないし，伋りにそのように計面したところて $\omega T$ の值が等上(たとえば オ の整数倍とか）にな るようにすることは困難であるがら $\omega T$ なる角は任 意の值をとるものと見なければならない．中えに

$$
\begin{aligned}
R= & \frac{A_{2}-A_{1}}{(P T / a)} \\
\leqq & \frac{A P T}{a \sqrt{\omega^{2}+\mu^{2}}}\left[e^{-\mu T}+1\right] \\
& +\frac{1}{T}\left[\frac{\lambda m-b}{\lambda^{2} m-b \lambda+a}+\frac{\lambda m+b}{\lambda^{2} m+b \lambda+a}\right]
\end{aligned}
$$

なる不等式を作つたとき，その右边が計测誤差の目安 となるものとみなさなくてはならないことになる。

なお弁の閉ぢ終り $t=T$ においては

$$
\begin{aligned}
(x)_{\boldsymbol{T}}=A & \sin (\omega T+\varphi) e^{-\mu T} \\
+ & P\left[\frac{1}{a}-\frac{1}{\lambda^{2} m+b \lambda+a}\right] \cdots \\
\left(\frac{d x}{d t}\right)_{T} & =A \omega \cos (\omega T+\varphi) e^{-\mu T} \\
& -A \mu \sin (\omega T+\varphi) e^{-\mu T} \\
& -P \frac{\lambda}{\lambda^{2} m+b \lambda+a} \cdots \cdots \cdots
\end{aligned}
$$

となりこれに相当する位置および運動エネルギーが

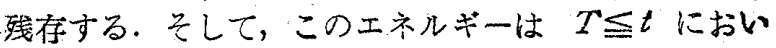
ては水銀社の自己班動となつて，第 2 図の点 $K$ 名ら

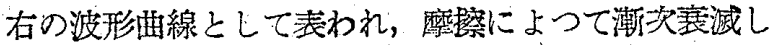
てゆく:

以上に求めた数式が，実際上どの程度の值になるか を諴べてみよう。奉際に作られている Gibson 計澌 装置の害情からおして，つぎのような場合を想定し， 数值計算を行つた。

$$
\begin{aligned}
& T=15 \mathrm{sec}, \quad \quad \omega_{0}=\frac{2 \pi}{3}=2, \\
& \lambda=k \pi / T, \quad k=2 \text { およひ } 4 ; \\
& \mu=b /(2 m)=1 / 3 \text { および } 1 / 6
\end{aligned}
$$

\begin{tabular}{|c|c|c|c|c|}
\hline & $\beta=1 / 3$ & $\mu=1 / 3$ & $\mu=1 / 6$ & $\mu=1 / 6$ \\
\hline & $k=2$ & $k=4$ & $k=2$ & $k=4$ \\
\hline \multirow{2}{*}{$A \sin \varphi$} & $1 P$ & $-1 P$ & $-1 P$ & $1 P$ \\
\hline & $146 \mathrm{~m}$ & $154 m$ & $-\overline{604} \bar{m}$ & $\overline{411} m$ \\
\hline$A \cos \varphi$ & $-\frac{1}{20} \quad D$ & $-\frac{1}{10} y$ & $-\frac{1}{20} \quad j$ & $-\frac{1}{11} j$ \\
\hline \multirow{2}{*}{$A$} & & 1 & 1 & 1 \\
\hline & $\overline{20}$ & $\overline{10}^{\prime \prime}$ & $\overline{20}$ & $\overline{11}$ \\
\hline$\varphi$ rad. & 0.137 & 0.065 & 0.033 & 0.027 \\
\hline$R \leqq$ & 0.0183 & 0.0346 & 0.0198 & 0.0355 \\
\hline \multirow{2}{*}{$(x)_{r}$} & $1 P$ & $1 P$ & $P$ & 1 \\
\hline & $\overline{42} \bar{m}$ & $\overline{18} \bar{m}$ & $\overline{58} \bar{m}$ & $\overrightarrow{22} \bar{m}$ \\
\hline \multirow{2}{*}{$\left(\frac{d x}{d t}\right)_{T}$} & $-\frac{1}{11}$ & $\frac{1}{\pi} \nu$ & $\frac{1}{11}$ & 1 \\
\hline & $11 \%$ & 7 & 11 & 6 \\
\hline
\end{tabular}

これに対する4通りの組合せについて第 1 表のごとき 数字がえられた。

以上に謂べたこと柄を䉍單に要約してみよう。第 3 図に示したような压力変動汃水生鉄管內におこるとき， 水銀桂の動きは（3）式で與えられるようになる。（3） 式の第 1 項注初期條件のために白己振動がおこること を示す。 $\omega$ 立自己振動の角速度（周波数 $\times 2 \pi ）$ である。
同式の第 2 項は强制振動を表わし，この項は匟力変動 の式 (1)とはかなり形がちがつており，水銀柱の質量 のために忠笑に庄力变動について行けないことを示す。 このために水銀杜の記錄から求めた面積 $A_{2}$ 、は压力 変動曲線の面積 $A_{1}$ といくらかの差を生ずる，その ために（8）式 $R$ で示すような誤差がでてくる.ある 発電所の军情から扎て $T=15$ 犁（闌鎖時）に対す る数値計算を行つたものか上表の数字である。こ〉で $\omega_{0}$ (摩擦のない水銀柱に対する自己振動の角速度) を 2 としな. その理由は現存する Gibson 記錄裝置の水 銀杜の自己振動周期が約 3 秒だからである。 $\mu=1 / 3$

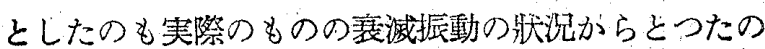
である. $k=2$ または 4 ととつたのは搨に計算の上の 仮定である.

第 1 表にかかげた数值よりつぎのごとく判断してよ

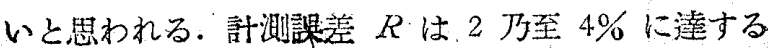
可能性があり，圧打变動曲線が銳い場合（k=4）には とくに增大する僓何がみられる。この誤差は計り方の

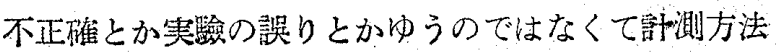
そのものに附隨して現われるものであるという点は大 いに注目せ标ばならな。もしこれを完全に除去しよ。 うとするなれば水銀柱を用いることを全然や就，他 の方法たとえば受王円板のフレによつて記錄する方法 などに改むべきであると考えられる。

なお (2) 式では衰減が $b d x / d t$ なる汧で表わされ るものとしたが，害情を見るに少くとも振り始め(第 2 図 $\left.O B_{1}\right)$ に抢いては $(d x / d t)^{2}$ に比例するものと考 えねばならないようである，その他にも細かい点はこ こに职り大れてない。

註:

（1）原稿骎附昭租 22 年 11 月 15 日，本要是安 
つて諭文化代える。

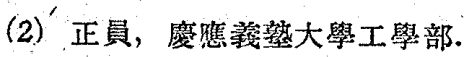

(3) N. R. Gibson, The Gibson Method and Apparatus etc., A. S. M. E., 1923.
(4) D. Thoma, Über den Genauigkeits grad des Gibsonschen Wassermetzverfahrens, Mittl. der Tech. Hochschule München, I.

\section{茸型油压弁の流量 係 数(1)}

油圧を使う機䋐において逃がし弁としてよく使われ

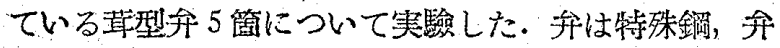
座は覲銅製で，第 1 図において，各邢の茾座の值㺯 $d_{m}$ (ただし $\left.2 d_{m}=d_{1}+d_{2}\right)$ は 11:9〜20.7 mm，并座の 斜面の長さは $0.73 \sim 1.1 \mathrm{~mm}$ ，䇧驗した升通路の最大 閶隐 $\delta_{\max }$ は $0.34 \sim 0.56 \mathrm{~mm}$ で, 最大揚程の湯合の
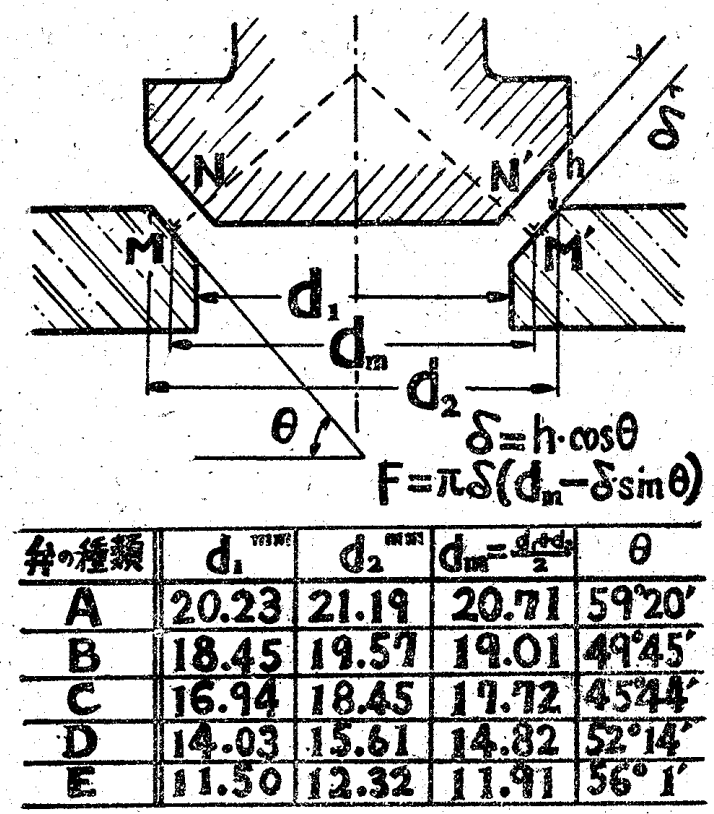

第 1 図

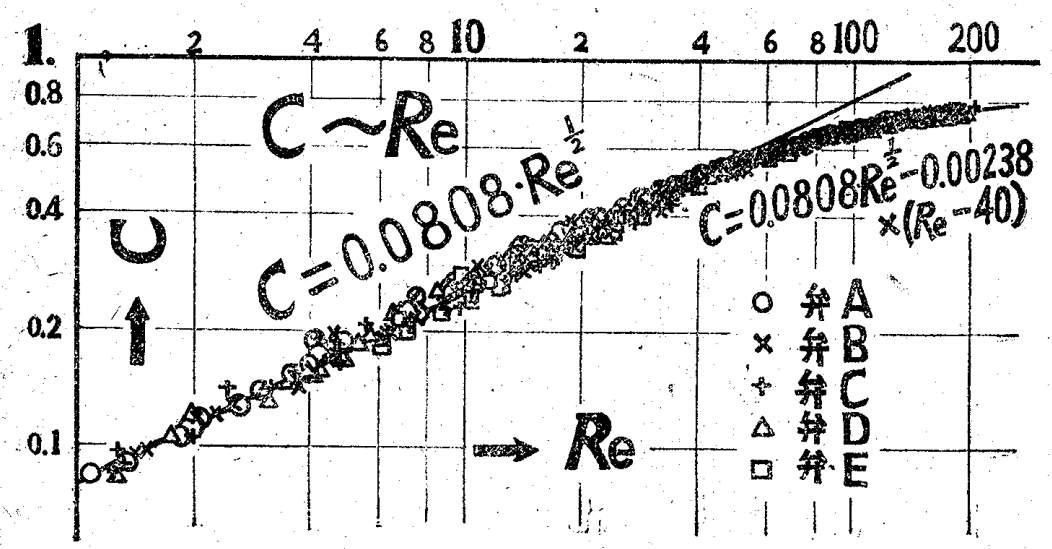

第 2 圆
板谷松樹 ${ }^{(2)}$ ，阔䝭 正 $^{(3)}$ ，舀森 清(4)

弁座の科䤃の長さ $S$ と通路の楅 $\delta_{\max }$ との比は約 2

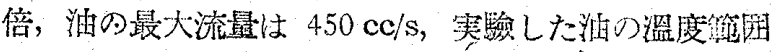
は 21 39 $9^{\circ} \mathrm{C}$ ，使用した油はダイナモ油で，美驗の結 果その此重さて㧍よび動粘性係数っはそれぞれ

$$
\gamma=0.9454-0.000596 \cdot t \quad(\mathrm{gr} / \mathrm{cc})
$$

$\log \cdot \log \nu=0.477-0.00739 \cdot t(\nu$ ：センチストークス)

で表わされた：笑驗はパイパスバルブの調節により 2〜8 氮压までの 7 種類の各一定压加のをとにおいて 会の湯程を変えて行つた。実驗結果恃第 2 図に示すご とく, 弁の流量係数 Cはレイノルズ数 $R_{e}=v \boldsymbol{\sigma} / \nu$ の 函数となつた。こつに。は弁と弁座の間踏で揚䖽を $h$ とすると $\delta=h \cos \theta$, であり，また $v$ は䄯座の中

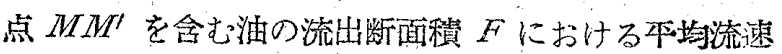
であり, 流量係数 $C$ は $Q=F v=C F \sqrt{2 g \cdot P / r}$ ，すな わち $C=Q / F \sqrt{2 g P / \gamma}$ である。このような整理方法を 用いた結果，流量係数 $C$ は搔の大きさ・揚程・圧力お 上び合座の角度の多少の相違にからわらず，すべてが 一本の曲線上に重なり，レイノルズ数の崡数となつた ことは面白いことと思われる. そして以上の結果より 流量係数 C.の実驗式として

$R_{e}<40$ の籍国では

$C=0.0808 R_{e^{2}}^{\frac{1}{2}}$

$40<R_{e}<200$ の螌田では

$C=0.0808 R_{e^{2}}-0.00238\left(R_{e}-40\right)$

なる式が得られた。

敦: :-

(1) 昭利 22 年 11 月 2 日, 講演会に おいて講演，原稿受附昭利 22 年 11 月 24 日，本諭文姴旨をもつて本諭交に代 j.

(2) 正貝, 東袁工鄴大学.

(3)（4）学生翼, 東京工業大学学生.” 